\title{
International trends in DM education
}

\author{
Karen Michelazzi \\ KMG Health Partners, East Toronto M4E 1G5, Canada. karen.michelazzi@kmghp.com
}

Background: KMG Health Partners has delivered education, consulting and return to work services to a diverse range of international customers and clients since 1996. Our team has been directly involved in the development of standards of practice across several countries, and has had the opportunity to engage with organisations from the commercial and government sector in Canada, the U.K., Iceland, Norway, Austria, Slovakia, Czech Republic, Netherlands, and Sweden.

Hypothesis: KMG has worked with organisations that are in various stages of development in their return to work, absence management, and disability management practices. KMG anticipated there would be common challenges, objectives, and desired outcomes amongst most countries.

Methods: KMG has modified our education programmes in various countries to ensure that the content is consistent with local legislation, policy, and current standards of practice. This has included discussion and analysis on current local practices, and subsequent recommendations for policy development, standards of practice, and service delivery for workers and employers. KMG regularly reviews and incorporates international best practices established by key agencies, including the International Labour Organisation, the World Health Organisation, International Social Services Agency, and NIDMAR.

Findings: Most countries have established or demonstrate a desire to establish best practice principles that are consistent with the 7 principles of effective disability management. Training and education that provides a common ideology for all stakeholders and meets both national and international best practice standards was observed to be a critical component to achieving success.

Conclusions: There are similarities in the challenges, objectives, and desired outcomes across many countries. Variances can be attributed to factors that include government legislation, cultural beliefs, and pre-existing social programmes. The delivery of training and education that meets national and international best practice standards is a critical component in establishing effective policies and best practice in absence and disability management. 